\title{
Poor antenatal care in 20 French districts: risk factors and pregnancy outcome
}

\author{
Béatrice Blondel, Barbara Marshall
}

\begin{abstract}
Study objective-Poor attendance to antenatal visits was studied to identify risk factors and to analyse the association with adverse pregnancy outcome.
\end{abstract}

Design-All poor attenders and a sample of good attenders were compared within three groups of women: women $<20$ years, French women $\geqslant 20$ years, and foreigners $\geqslant 20$ years.

Setting-20 French districts including 85000 births from January to June 1993. Subjects -848 poor attenders and 759 good attenders. Poor attenders made fewer than four antenatal visits or began care during or after the sixth month. Good attenders made at least four visits and began care before the sixth month.

Main results-1.1\% of the women were poor attenders. Risk factors for poor attendance were single status and lack of health insurance in the group under 20; young age, high parity, and single status in the French group aged over 20; and single status and lack of health insurance in the foreign group aged over 20. For poor attenders, the odds ratios for preterm delivery were 5.8 (95\% CI: $3.2,10.5)$ among French women and 3.3 (95\% CI: $1.5,7.4)$ among foreign women with health insurance. Poor attendance was not associated with poor pregnancy outcome in the group under 20, and among foreign women over 20 without health insurance, but both groups had high rates of preterm delivery and low birth weight.

Conclusion-Lack of health insurance is an important barrier to health care during pregnancy. Poor antenatal care is an important risk factor for adverse pregnancy outcome among women who have easy access to health care services.

(F Epidemiol Community Health 1998;52:501-506)

Debate on the medical benefits of antenatal care is ongoing. Antenatal programmes currently practised contain a substantial number of visits, up to as many as $14^{1}$ and recently the effectiveness of such care in discovering pregnancy complications or obstetric risk conditions has been considered in several countries. $^{23}$ A redefinition of the content of care has been proposed as well as a reduction in the number of visits. ${ }^{4}$ Randomised controlled trials conducted in the UK, the USA, and Zimbabwe showed that good perinatal outcomes were maintained when the number of antenatal visits was a little less than those of the standard care..$^{5-7}$
To better understand the relation between antenatal care and pregnancy outcome, and to assess the benefits of care, many observational studies have focused on the adequacy of care. Indicators of adequacy usually compared the initiation of care and the following number of visits actually done with the schedule of visits recommended by obstetricians in the countries undertaking the studies. ${ }^{8-11}$ The rates of preterm delivery or low birth weight were not always higher among women with inadequate care than among the other women, after adjusting for the main risk factors. ${ }^{9}{ }^{10}$ Nevertheless the threshold to distinguish between adequate and inadequate care was often high and many women with inadequate care actually had a great number of visits or early initiation of care. It is thus difficult to say that inadequate care means lack of care.

Other studies showed that no care or very little care is associated with low birth weight, from data in the overall population in the USA, ${ }^{12-15}$ or in hospital-based populations in various countries, such as the USA, ${ }^{16}{ }^{17}$ Australia, ${ }^{18}$ France, ${ }^{19}$ Israel ${ }^{20}$ or Sweden. ${ }^{21}$ Most of the studies were conducted a long time ago. They were mainly from the USA, where health insurance coverage is limited, and no or very poor care was not rare. Thus it is interesting to study the present situation of women with no or very poor care in a different country, where financial barriers are not so important, a large amount of money is given to women who followed the recommended schedule of visits, and women with no or very poor care are a small minority. ${ }^{22}$

In France, seven visits are recommended for normal pregnancies. There are some financial barriers to access to health services during pregnancy. Free care is provided in the Maternal and Child Health clinics, but these clinics are very few. Thus most women usually pay the full cost of care or part of it and they are subsequently reimbursed, if they have health insurance.

Health insurance coverage depends on social situation. French women and legal immigrants have similar rights for health insurance. Employed women and women with unemployment benefits are insured as are women living with an employed partner or a partner receiving unemployment benefits. Furthermore most women with no or low resources live on social benefits (which include the "Single Mother Allowance" and the "Minimum Income for Integration") and are thereby automatically insured. However, illegal immigrants cannot be insured. 
Table 1 Antenatal care of poor attenders among women under 20, French women, and foreigners

\begin{tabular}{llll}
\hline & $\begin{array}{l}<20 \text { years } \\
(n=97) \%\end{array}$ & $\begin{array}{l}\geqslant 20 \text { years } \\
\text { French women } \\
(n=400) \%\end{array}$ & $\begin{array}{l}\geqslant 20 \text { years } \\
\text { Foreigners } \\
(n=282) \%\end{array}$ \\
\hline Number of visits & 32.0 & 26.0 & \\
$\quad 0$ & 26.8 & 36.5 & 22.0 \\
$1-2$ & 19.6 & 22.5 & 39.0 \\
3 & 21.6 & 15.0 & 12.4 \\
$\quad \begin{array}{l}\text { Start of care } \\
\text { 1st-3rd month }\end{array}$ & 6.1 & 13.8 & 13.5 \\
4th-6th month & 19.7 & 17.5 & 16.3 \\
7 th-9th month & 74.2 & 68.7 & 70.2 \\
\hline
\end{tabular}

We carried out a survey in 1993 to investigate the consequences of poor antenatal care and assess the contributions of the health care system and other factors. In this paper we study the main risk factors of poor attendance at antenatal visits and we evaluate the impact of poor care on the health status of newborns.

\section{Methods}

STUDY POPULATION

Women who gave birth between January and June 1993 in all the maternity units of 20 districts were included. In these districts, there were 85066 births during the survey period $(23 \%$ of all births in France during this period)..$^{23}$

Poor attenders were identified in the maternity units when they delivered, or when they were admitted after an unplanned home delivery. To assess antenatal care we took into account the number of visits to an outpatient clinic or any other medical service involving obstetric examination by a physician or midwife. Emergency visits followed by hospital admission were included, except if the delivery occurred within 24 hours. Women were defined as poor attenders if they had attended fewer than four visits or if they had begun antenatal care during the last three months of pregnancy. The good attenders included women who had attended four visits or more, the first of which had been during the first six months of pregnancy.

We considered three groups separately: women under 20, French women who were 20 years old or more, and foreigners 20 years old or more. These groups were choosen because we surmised that lack of care expressed different situations for these three groups, mainly denial of pregnancy among very young women and social or cultural barriers among immigrants. To get a sample of good attenders, we selected for each poor attender the next delivery in the same maternity unit. For example when we found a woman under 20 with less than four visits, we took the first good attender under 20 who delivered after this woman.

A total of 903 poor attenders were identified. A questionnaire was filled in from the medical records for every poor attender and good attender included in the study. In three districts data were collected in the public units only and, in one district, in the two main public hospitals only. We obtained data for 848 poor attenders and 759 good attenders. Among the poor attenders 69 women remained anony- mous because they wanted to abandon their child. They were excluded from the analysis and we did not select the corresponding good attenders, as we did not know their social and demographic characteristics. For 20 poor attenders, no good attender delivered before the end of the survey. The analysis was thus based on 779 poor attenders and 759 good attenders. As data were missing from some records, the number of women studied differs between different variables.

Poor attenders were compared with good attenders within the three subgroups: women under 20 years old, thereafter referred to as women under 20, French women over 20 years old (French women), and foreigners over 20 years old (foreign women). We first described antenatal care for poor attenders. We then studied the risk factors for poor attendance. To identify independent risk factors, logistic regressions were performed using social and demographic characteristics as independent variables. We estimated adjusted odds ratios for poor attendance and their $95 \%$ confidence intervals. Finally we studied the relation between poor attendance and adverse pregnancy outcomes: infant death before discharge, preterm delivery (gestational age $<37$ full weeks), low birth weight $(<2500 \mathrm{~g})$, and admission to a special care unit. To control for potential confounding factors, logistic regressions were performed and we estimated the adjusted odds ratios for preterm delivery and birth weight under $2500 \mathrm{~g}$, and their corresponding confidence intervals.

\section{STATISTICS}

The $\chi^{2}$ test was used to compare poor and good attenders. We used the SAS statistical package for univariate analyses, and the BMDP package for logistic regressions. The study was approved by the the National Committee of Computerized Data and Civil Liberty.

\section{Results}

In the participating districts $1.1 \%$ of women were poor attenders. In this group $32 \%$ of the women under $20,26 \%$ of the French women, and $22 \%$ of the foreign women attended no visits (table 1). Among the women who had made at least one visit, $6 \%$ of the women under 20 and $14 \%$ of the older women began antenatal care during the first three months of pregnancy. In the control group the mean number of visits was 8.8 among the women under 20 and the French women and 8.6 among the foreign women.

Poor attenders were younger than good attenders, in the group under 20 and in the French group (table 2). Poor attenders were of higher parity than good attenders, in the French group. Poor attenders were more often single and without health insurance than the good attenders in all three groups.

Logistic regression analysis showed that among the women under 20, risk factors for poor attendance were young age, single status, and lack of health insurance (table 3). Among the French women the risk of poor attendance decreased with age and increased with parity. It 
Table 2 Characteristics of poor and good attenders among women under 20, French women, and foreigners

\begin{tabular}{|c|c|c|c|c|c|c|c|c|c|}
\hline & \multicolumn{3}{|l|}{$<20$ years } & \multicolumn{3}{|c|}{$\geqslant 20$ years French women } & \multicolumn{3}{|c|}{$\geqslant 20$ years Foreigners } \\
\hline & $\begin{array}{l}\text { Poor attenders } \\
(n=97) \%\end{array}$ & $\begin{array}{l}\text { Good } \\
\text { attenders } \\
(n=80) \%\end{array}$ & $p$ Value & $\begin{array}{l}\text { Poor attenders } \\
(n=400) \%\end{array}$ & $\begin{array}{l}\text { Good } \\
\text { attenders } \\
(n=400) \%\end{array}$ & p Value & $\begin{array}{l}\text { Poor attenders } \\
(n=282) \%\end{array}$ & $\begin{array}{l}\text { Good } \\
\text { attenders } \\
(n=279) \%\end{array}$ & $p$ Value \\
\hline \multicolumn{10}{|l|}{ Age (y) } \\
\hline$<18$ & 34.0 & 12.5 & & & & & & & \\
\hline $18-19$ & 66.0 & 87.5 & $<0.01$ & & & & & & \\
\hline $20-24$ & & & & 37.3 & 20.0 & & 29.8 & 22.2 & \\
\hline $25-29$ & & & & 28.2 & 39.0 & & 30.8 & 33.3 & \\
\hline $30-34$ & & & & 18.0 & 28.2 & $<0.001$ & 25.2 & 28.7 & NS \\
\hline$\geqslant 35$ & & & & 16.5 & 12.8 & & 14.2 & 15.8 & \\
\hline \multicolumn{10}{|l|}{ Parity* } \\
\hline 0 & 87.6 & 81.2 & & 32.5 & 40.1 & & 35.7 & 36.7 & \\
\hline 1 & $12.4 \dagger$ & $18.8 \dagger$ & NS & 20.7 & 35.8 & & 30.7 & 23.4 & \\
\hline 2 & & & & 14.5 & 14.5 & $<0.001$ & 12.5 & 15.1 & NS \\
\hline 3 & & & & 13.5 & 6.8 & & 9.7 & 11.9 & \\
\hline$\geqslant 4$ & & & & 18.8 & 2.8 & & 11.4 & 12.9 & \\
\hline \multicolumn{10}{|l|}{ Marital status ${ }^{\star}$} \\
\hline married & 8.3 & 31.3 & & 19.6 & 58.8 & & 53.3 & 78.5 & \\
\hline cohabiting & 11.3 & 23.7 & $<0.001$ & 36.7 & 31.7 & $<0.001$ & 15.2 & 11.3 & $<0.001$ \\
\hline single & 80.4 & 45.0 & & 43.7 & 9.5 & & 31.5 & 10.2 & \\
\hline No health insurance ${ }^{\star}$ & 23.2 & 6.4 & $<0.01$ & 13.6 & 0.3 & $<0.001$ & 71.3 & 17.8 & $<0.001$ \\
\hline
\end{tabular}

${ }^{\star}$ Data were missing for one to four women within the groups. $\dagger$ For parity 1 and 2 .

Table 3 Adjusted odds ratios (OR) for poor attendance among women under 20, French women, and foreigners

\begin{tabular}{|c|c|c|c|c|c|c|}
\hline & \multicolumn{2}{|c|}{$<20$ years $(n=173)$} & \multicolumn{2}{|c|}{$\begin{array}{l}\geqslant 20 \text { years French } \\
\text { women }(n=795)\end{array}$} & \multicolumn{2}{|c|}{$\begin{array}{l}\geqslant 20 \text { years Foreigner } \\
(n=542)\end{array}$} \\
\hline & $O R_{a}$ & $95 \% C I$ & $O R_{a}$ & $95 \% C I$ & $O R_{a}$ & $95 \% C I$ \\
\hline \multicolumn{7}{|l|}{ Age $(y)$} \\
\hline$<18$ & 2.8 & $1.2,6.6$ & & & & \\
\hline $18-19$ & 1 & & & & & \\
\hline $20-24$ & & & 3.4 & $2.2,5.3$ & 1.6 & $0.9,2.9$ \\
\hline $25-29$ & & & 1 & & 1 & \\
\hline $30-34$ & & & 0.6 & $0.4,1.0$ & 1.0 & $0.6,1.8$ \\
\hline$\geqslant 35$ & & & 0.6 & $0.3,1.1$ & 1.1 & $0.6,2.2$ \\
\hline \multicolumn{7}{|l|}{ Parity } \\
\hline 0 & 1 & & 1 & & 1 & \\
\hline 1 & $0.7^{\star}$ & $0.3,1.9$ & 1.5 & $1.0,2.4$ & 1.8 & $1.0,3.1$ \\
\hline 2 & & & 3.4 & $2.0,5.8$ & 1.6 & $0.8,3.1$ \\
\hline 3 & & & 9.6 & $5.0,18.3$ & 2.0 & $0.9,4.2$ \\
\hline$\geqslant 4$ & & & 34.9 & $15.7,77.8$ & 2.2 & $1.0,4.7$ \\
\hline Single & 6.3 & $2.8,14.1$ & 9.3 & $6.0,14.3$ & 3.3 & $1.9,5.6$ \\
\hline No health insurance & 7.6 & $2.2,26.8$ & $\dagger$ & & 12.2 & $7.8,18.9$ \\
\hline Foreigner & 0.7 & $0.2,2.0$ & & & & \\
\hline
\end{tabular}

${ }^{\star} \mathrm{OR}_{\mathrm{a}}$ for parity 1 or $2 .+$ Estimation of the $\mathrm{OR}_{\mathrm{a}}$ is difficult because of the small number of women without health insurance coverage in the control group. The variable was therefore not included in the model.

was higher for single women. Among the foreign women, the risk was higher, but not significantly, among young or multiparous women. Poor attendance was associated with single status and health insurance; for women without insurance coverage the odds ratio was 12.2 (95\% CI: 7.8, 18.9).

In the three groups, the health status of infants of poor attenders was poorer than that of infants of good attenders (table 4). However, differences for preterm delivery, low birth weight, and admission to special care units were only significant for the French group.
In the multivariate analysis, poor attendance was not significantly associated with preterm delivery and low birth weight among women under 20 but the odds ratio for preterm delivery was 2.0 (table 5). Among French women who were poor attenders, the odds ratios were 5.8 (95\% CI: 3.2, 10.5) for preterm delivery and $2.6(95 \% \mathrm{CI}: 1.5,4.4)$ for low birth weight. Among foreign women, an interaction between poor attendance and health insurance coverage was found for preterm delivery $(p=0.06)$ and low birthweight $(\mathrm{p}=0.04)$. The odds ratios were estimated, taking good attenders with health insurance as the reference group. For preterm delivery, the odds ratios for poor attendance were 3.3 (95\% CI: 1.5, 7.4) among women with insurance and 1.6 (95\% CI : 0.4, 7.5) among women without insurance. For low birth weight, the odds ratios were 2.9 (95\% CI: $1.2,7.1)$ and 2.2 (95\% CI: $0.5,10.6)$ respectively in the two groups.

Although the relation between poor attendance and pregnancy outcome was not statistically significant among women under 20 and foreign women without health insurance, the pregnancy outcome in these two groups was very poor. Among poor attenders the preterm delivery rate was $9.4 \%$ for women under 20 and $10.0 \%$ for foreigners without health insurance.

\section{Discussion}

This population-based study shows that very few women in France received little or no antenatal care. The risk factors of being a poor attender varied according to age and nationality.

Table 4 Pregnancy outcome for poor and good attenders among women under 20, French women, and foreigners

\begin{tabular}{|c|c|c|c|c|c|c|c|c|c|}
\hline & \multicolumn{3}{|l|}{$<20$ years } & \multicolumn{3}{|c|}{$\geqslant 20$ years French women } & \multicolumn{3}{|c|}{$\geqslant 20$ years Foreigners } \\
\hline & $\begin{array}{l}\text { Poor } \\
\text { attenders } \\
(\%)\end{array}$ & $\begin{array}{l}\text { Good } \\
\text { attenders } \\
(\%)\end{array}$ & p Value & $\begin{array}{l}\text { Poor attenders } \\
(\%)\end{array}$ & $\begin{array}{l}\text { Good } \\
\text { attenders (\%) }\end{array}$ & $p$ Value & $\begin{array}{l}\text { Poor attenders } \\
(\%)\end{array}$ & $\begin{array}{l}\text { Good } \\
\text { attenders } \\
(\%)\end{array}$ & p Value \\
\hline \multicolumn{10}{|l|}{ Health status } \\
\hline stillbirth & 2.1 & 1.3 & & 1.7 & 0.2 & & 3.2 & 0.7 & \\
\hline death before discharge & 0.0 & 0.0 & NS & 0.7 & 0.5 & NS & 1.0 & 0.4 & NS \\
\hline alive at discharge & $97.9(97)$ & $98.7(80)$ & & $97.6(402)$ & $99.3(404)$ & & $95.8(285)$ & $98.9(283)$ & \\
\hline Gestational age $<37$ weeks & $9.4(96)$ & $6.2(80)$ & NS & $19.0(395)$ & $5.2(404)$ & $<0.001$ & $12.5(281)$ & $7.8(282)$ & NS \\
\hline Birthweight $<2500 \mathrm{~g}$ & $8.2(97)$ & $8.8(80)$ & NS & $16.2(401)$ & $7.2(404)$ & $<0.001$ & $10.6(283)$ & $6.7(283)$ & NS \\
\hline Admission to special care unit & $14.6(96)$ & $13.9(79)$ & NS & $26.3(395)$ & $11.2(403)$ & $<0.001$ & $16.2(278)$ & $11.7(281)$ & NS \\
\hline
\end{tabular}


Table 5 Adjusted odds ratios for poor pregnancy outcome for poor attenders compared with good attenders among women under 20, French women, and foreigners

\begin{tabular}{|c|c|c|c|c|}
\hline & \multicolumn{2}{|c|}{ Preterm delivery } & \multicolumn{2}{|c|}{ Low birth weight } \\
\hline & $O R_{a}$ & $95 \% C I$ & $O R_{a}$ & $95 \% C I$ \\
\hline \multicolumn{5}{|l|}{$<20$ years } \\
\hline $\begin{array}{l}\text { poor attendance } \\
\geqslant 20 \text { years }\end{array}$ & 2.0 & $0.5,7.6$ & 1.1 & $0.3,3.6$ \\
\hline $\begin{array}{l}\text { French women } \\
\text { poor attendance }\end{array}$ & 5.8 & $3.2,10.5$ & 2.6 & $1.5,4.4$ \\
\hline \multicolumn{5}{|l|}{$\begin{array}{l}\geqslant 20 \text { years } \\
\text { foreigners }\end{array}$} \\
\hline poor attendance and health insurance & 3.3 & $1.5,7.4$ & 2.9 & $1.2,7.1$ \\
\hline poor attendance no health insurance & 1.6 & $0.4,7.5$ & 2.2 & $0.5,10.6$ \\
\hline
\end{tabular}

$\bar{\star}$ Interaction between antenatal care and health insurance coverage. The reference group is good attenders with health insurance.

Among women under 20 and French women, several maternal social and demographic characteristics were related to the use of health services. The lack of health insurance was the major factor for poor attendance among foreign women. An influence of poor attendance on pregnancy outcome was observed only among French women and foreigners with health insurance coverage.

The districts included in the survey represented about $20 \%$ of the total number of births in France. Every district participated on a voluntary basis and thus the proportion of poor attenders in the participating districts may not be the same as in the other districts. However, data from a national sample of births in $1995^{22}$ shows that the proportion of women attending fewer than four visits was similar in the districts included and not included in our study.

Our definition of poor attendance during pregnancy is based on French health policy: one year before the study, the legal minimum number of visits was four for a full term pregnancy. Since 1992, the schedule for visits has been: beginning of care during the first three months and thereafter one visit per month from the fourth to the ninth month. This recommendation has had a great impact as, at the time of the study, maternity benefits (Fr 8325, £965) were only payable if the woman followed the schedule. Since 1992 the minimum number of visits has been seven for a full term pregnancy and four when the pregnancy ends at about 26 weeks of gestation. The threshold of four visits thus represents the minimum number of compulsory visits for most women who had preterm delivery.

Only three women (one in the French group and two in the foreign group) of the 119 poor attenders who had a preterm newborn delivered before 26 weeks of gestation and thus had insufficient time to make four visits, even if they had followed the recommended schedule. Thus the relation between poor attendance and preterm delivery cannot be fully explained by the length of gestation.

Health insurance coverage was the main risk factor for poor attendance in our study. However its contribution was underestimated for two reasons. Firstly, coverage was known at delivery. Some women without health insurance at the beginning of pregnancy may have had contact with a social worker during pregnancy and consequently been able to obtain insurance before delivery. This would undoubtedly be more frequent among poor attenders. Secondly, poor attenders were compared with women who delivered in the same maternity units. This choice may underestimate the differences between the two groups as poor attenders deliver in units that recruit a large proportion of women from the low social classes. In our survey good attenders did not differ very much from the overall population of pregnant women in the same districts for age, parity, and single status. ${ }^{22}{ }^{23}$ Nevertheless there were differences for health insurance. According to the national sample of birth in $1995,{ }^{22}$ $6.3 \%$ of foreign women with at least four visits had no insurance coverage at the time of delivery, whereas this was the case for $17.8 \%$ of the good attenders in our study. Consequently the role of lack of health insurance was highly underestimated in our survey.

Lack of health insurance is an important barrier to medical care in the population, as has been shown in the USA where many women are uninsured. ${ }^{24}{ }^{25}$ In our study few French women over 20 years old had no insurance whereas this was prevalent in the other groups, and was an important factor for poor attendance, especially among foreigners. For foreigners lack of insurance is often associated with illegal status whereas for French women, it may stem from lack of knowledge about social rights or reluctance to meet social workers or to speak about the pregnancy, especially for the youngest women.

The risk factors for poor care appeared to vary according to age and nationality. It is observed for health insurance, and also for age and parity. Young age and high parity, which are well known risk factors of inadequate antenatal care, ${ }^{26}$ are associated with poor care among women under 20 and French women, whereas this relation is weak among foreigners. Furthermore, interviews with a subsample of women two months after delivery suggest that the reasons for the lack of care and the barriers to access to health services are different in the three groups. ${ }^{27} 28$ Most women under 20 reported that they received little or no care because they did not know that they were pregnant, they did not want the pregnancy or they wanted to hide their situation from their family. Among French women over 20, the main reasons were an unwanted pregnancy or serious worries, mainly about unemployment, marital conflicts, and financial difficulties. The foreigners frequently said that they could not receive antenatal care because they were illegal immigrants, they cannot get health insurance, they arrived recently in France or they had serious worries because they were homeless, unemployed or poor. Thus the lack of care was associated with the woman's attitude to the pregnancy in at least $50 \%$ of young or French women whereas the social situation of the family was the reason most commonly given by foreign women.

In our study preterm delivery rate was higher among poor attenders than among good attenders in each studied group: the association was not statistically significant among women 
under 20 or foreigners without health insurance, but was highly significant among French women and foreigners with health insurance. The differences between the four groups cannot be explained by disparities in the amount of antenatal care because the difference between the mean number of visits for poor and good attenders was 6.6 among women under 20, 5.6 among foreigners without health insurance, 6.8 among French women, and 6.2 among foreigners with health insurance.

Several population-based studies have shown strong associations between very poor antenatal care and pregnancy outcome. ${ }^{12-15}$ Nevertheless it was found in the 1970 British Births Survey that delayed antenatal care was not linked to adverse pregnancy outcome, among the group of women who were certain of the date of their last menstrual period. ${ }^{29}$

In our study, similar to other observational studies of very poor care, the risk associated with lack of care is difficult to assess. ${ }^{30}$ It is not easy to distinguish between the contribution of the lack of medical care and that of the social situation of the women. It was found that the risk of having a preterm or small birthweight baby was higher if antenatal care was low, after controlling for sociodemographic factors such as age, parity, educational level or family status, ${ }^{14} 1520$ or after adjusting for health habits $^{31}$ or for indicators of underpriviledged situation (lack of health insurance, refugee status or financial hardship ${ }^{19}$ ), as was observed in our study.

Another difficulty in the assessment of antenatal care is related to pregnancy complications. Women who are reluctant to seek medical care often make a large number of visits when subsequently they suffer disease or present with symptoms. The proportion of poor attenders with complications, and consequently with adverse pregnancy outcome, is thus lower than that of good attenders, causing the effect of poor care to be underestimated. This underestimation may have been substantial among women under 20 and foreign women without health insurance, because these women are not expected to make a large number of visits for numerous reasons (including illegal status, cost of care, and unsuspected pregnancy). This could explain why the relation between poor care and pregnancy outcome was small and not significant in these two groups.

As there is no randomised controlled trial comparing women without care or a very small number of visits to women with adequate care, we cannot state that antenatal visits are beneficial. Nevertheless several factors suggest that there is a relation between antenatal care and pregnancy outcome. Most studies on very low care showed a relation between lack of care and pregnancy outcome and the corresponding odds ratios for low birth weight were often high, between 2 and $5 .{ }^{12-21}$ Furthermore a relation was also observed in populations who had no care because of religion or lack of local antenatal services, ${ }^{33} 34$ and consequently who had not the selection biais usually found in the other studies. Thus Moore et $a l^{\beta 4}$ found that indigent women who received care in a prenatal care programme had a small rate of low birthweight babies compared with women with similar risk factors who were on the waiting list for enrollment.

Psychological factors may also affect the relation between lack of care and pregnancy outcome. Lack of medical care often results from negative attitude toward pregnancy. ${ }^{35-38}$ For women who are unhappy or ambivalent about their pregnancy, seeking medical care would force them to face being pregnant, a situation they prefer to ignore. A study based on interviews with women with low care in the suburbs of Paris suggests that not seeking antenatal care is an expression of extreme psychological distress among French women. ${ }^{39}$ The pregnancy may also bring memories of painful events experienced during childhood, which prevent women from coping with the pregnancy. ${ }^{40}$ An unfavourable psychological environment may increase the preterm delivery rate and the incidence of low birth weight as these outcomes are associated with negative attitudes toward pregnancy and unsatisfactory psychological status. ${ }^{41-45}$ It is possible that the influence of psychological factors was very important among French women and foreign women with health insurance, as these women confront no major structural barriers to health care services.

In conclusion, pregnant women who receive poor antenatal care make up a heterogeneous group: they display a variety of risk factors and pregnancy outcomes differ. Various strategies could be developed for encouraging women to enrol in care. Lack of insurance is the main barrier to medical care, especially for foreign women. Thus free care or universal health insurance to pregnant women would improve access to health care services in France.

The effect of poor care on infant health is partly because of the insufficient screening and treatment and partly because of the psychological and social environment of the women. Special attention should be paid to women who are confronted with no major structural barrier to medical care, so as to prevent poor pregnancy outcome, to encourage a good mother-child relationship, and to help women to overcome their psychological distress.

This study was conducted in collaboration with the Direction Générale de la Santé (Ministry of Labour and Social Affairs) and the Maternal and Child Health Services. I am grateful for the assistance of the maternity wards. My thanks also go to Monique Kaminski and Gérard Bréart for their helpful comments.

1 Blondel B, Pusch D, Schmidt E. Some characteristics of antenatal care in 13 European countries. $\mathrm{Br} F$ Obstet Gynaecol 1985;92:565-8.

2 Hall $\mathrm{MH}$, Chng PK, MacGillivray I. Is routine antenatal care worthwhile? Lancet 1980;ii:78-80.

3 Backe B, Nakling J. Effectiveness of antenatal care: a population based study. Br f Obstet Gynaecol 1993;100:727-32.

4 Villar J, Bergsiø P. Scientific basis for the content of routine antenatal care. Philosophy, recent studies, and power to liminate or alleviate adv, recer to liminate or alleviate adverse maternal outcomes. Acta

5 McDuffie RS, Beck A, Bischoff K, et al. Effects of frequency of prenatal care visits on perinatal outcome among low-risk women. A randomized controlled trial. $7 A M A$ 1996;275: $847-51$. 
6 Munjanja SP, Lindmark G, Nystrom L. Randomised controlled trial of a reduced-visits programme of antenata
care in Harare, Zimbabwe. Lancet 1996;348:364-9.

7 Sikorski J, Wilson J, Clement S, et al. A randomized controlled trial comparing two schedules of antenatal visits: the antenatal project. BMF 1996;312:546-53.

8 Kotelchuck $M$. The adequacy of prenatal care utilisation index. Its US distribution and association with low birthweight. Am f Public Health 1994;84:1486-9.

9 Wulf KH, Steck T. The impact of timing and frequency of prenatal visits on the outcome of pregnancy in the perinatal registry of Bavaria 1987-1988. Eur f Obstet Gynecol Reprod Biol 1994;57:79-84.

10 Gissler M, Hemminki E. Amount of antenatal care and infant outcome. Eur f Obstet Gynecol Reprod Biol 1994;56: 9-14.

11 Delgado-Rodriguez M, Gomez-Olmedo M, BuenoCavanillas A, et al. A comparison of two indices of adequacy of prenatal care utilization. Epidemiology 1996;7: 648-50.

12 Gortmaker SL. The effects of prenatal care upon the health of the newborn. Am F Public Health 1979;69:653-60.

13 Eisner V, Brazie JV, Pratt MW, et al. The risk of low birthweight. Am f Public Health 1979;69:887-93.

14 Greenberg RS. The impact of prenatal care in different social groups. Am f Obstet Gynecol 1983;145:797-801.

15 Gould JB, Le Roy S. Socio economic status and low birth weight: a racial comparison. Pediatrics 1988;82:896-904.

16 Ryan GM, Sweeney PJ, Solola AS. Prenatal care and pregnancy outcome. Am F Obstet Gynecol 1980;137:876-81.

17 Leveno KJ, Cunningham G, Roark ML, et al. Prenatal care and low birth weight infant. Obstet Gynecol 1985;66:599605.

18 Keeping JD, Chang AMZ, Morrison J, et al. Poor antenatal attendance and obstetric performance. Aust N Z F Obstet Gynaec 1980;20:139-43.

19 Blondel B, Dutilh P, Delour M, et al. Poor antenatal care and pregnancy outcome. Eur f Obstet Gynecol Repr Biol and pregnancy

20 Insler V, Larholt K, Hagay ZJ, et al. The impact of prenatal care on the outcome of pregnancy. Eur $\mathcal{f}$ Obstet Gynecol Repr Biol 1986;23:211-23.

21 Donaldson PJ, Billy JOG. The impact of prenatal care in birthweight. Med Care 1984;22:177-88.

22 Blondel B, Bréart G, du Mazaubrun C, et al. La situation périnatale en France. Evolution entre 1981 et 1995. F Gynecol Obstet Biol Repr 1997;26:770-80.

23 Couet C, Tamby I. La situation démographique en 1991 Collection INSEE 1993;26:91-117.

24 Cooney JP. What determines the start of prenatal care. Prenatal care, insurance and education. Med Care 1985;23 986-7.

25 Coburn AF, McDonald TP. The effects of variations in AFDC and Medicaid eligibility on prenatal care use. Soc Sci Med 1992;35:1055-63.

26 Goldenberg RL, Patterson ET, Freese MP. Maternal demographic, situational and psychosocial factors and their relationship to enrollment in prenatal care : a review of the literature. Women Health 1992;19:133-51.
27 Blondel B, Marshall B. Les femmes peu ou pas suivies pendant la grossesse, résultats d'une étude dans 20 départements. F Gynecol Obstet Biol Repr 1996;25:515-22.

28 Blondel B. Pourquoi y a-t-il encore des grossesses peu ou pas suivies? Dossiers d'Obstétrique 1996;241:3-7.

29 Thomas P, Golding J, Peters TJ. Delayed antenatal care: does it effect pregnancy outcome? Soc Sci Med 1991;32: $715-23$

30 Blondel B. Utilité du suivi des grossesses: risque des grossesses peu ou pas suivies. Presse Med 1995;24:1015-16.

31 Florey C, Taylor DJ. The relation between antenatal care and birthweight. Rev Epidemiol Sante Publique 1994;42: 191-7.

32 Binsacca DB, Ellis J, Martin D, et al. Factors associated with low birthweight in an inner-city population. The role of financial problems. Am 7 Public Health 1987;77:505-6.

33 Kaunitz AM, Spence C, Danielson TS, et al. Perinatal and maternal mortality in a religious group avoiding obstetric care. Am f Obstet Gynecol 1984;150:826-31.

34 Moore TM, Origel W, Key TC, et al. The perinatal and economic impact of prenatal care in a low-socioeconomic population. Am f Obstet Gynecol 1986;154:29-33.

35 Krieger JW, Connell FA, Logerfo JP. Medicaid prenatal care : a comparison of use and outcomes in fee for service and managed care. Am f Public Health 1992;82:185-90.

36 Lia-Hoagberg B, Rode P, Skovholt CJ, et al. Barriers and motivators to prenatal care among low-income women. Soc Sci Med 1990;30:487-95.

37 Petiti D, Coleman C, Binsacca D, et al. Early prenatal care in urban black and white women. Birth 1990;17:1-5.

38 Sable MR, Stockbauer JW, Schramm WF, et al. Differentiating the barriers to adequate prenatal care in Missouri. Public Health Rep 1990;105:549-55.

39 Arondel F, Nonain N. Future mère, quel suivi? Saint Denis: Rapport de la Direction Médicale de Saint Denis, 1993.

40 Bonnet C. Geste d'amour, l'accouchement sous X. Paris: Odile Jacob, 1990.

41 Mamelle N, Masson A, Munoz F, et al. Development and use of a self-administered questionnaire for assessement of psychological attitudes toward pregnancy and their relation to a subsequent premature birth. Am f Epidemiol 1989;130: 989-98.

42 Hedegaard M, Henriksen TB, Sabroe S, et al. Psychological distress in pregnancy and preterm delivery. BMF 1993;307: 234-9.

43 Hoffman S, Hatch MC. Stress, social support and pregnancy outcome : a reassessement based on recent research. Paediatr Perinat Epidemiol 1996;10:380-405.

44 Rothberg AD, Lits B. Psychological support for maternal stress during pregnancy: effect on birthweight. Am f Obstet Gynecol 1991;165:403-7.

45 Norbeck JS, Dejoseph JF, Smith RT. A randomized trial of an empirically-derived social support intervention to prevent low birthweight among African-american women. Soc Sci Med 1996;43:947-54. 